\title{
Contribuições psicanalíticas na compreensão do cuidado em saúde mental no Brasil: revisão de literatura
}

\author{
Psychoanalytic Contributions to the Understanding of \\ Mental Health Care in Brazil: A Literature Review
}

\author{
João Paulo Nogueira da Silva ${ }^{1}$ \\ https://orcid.org/0000-0003-4446-5021 \\ Carolina Ventura Silva² \\ D https://orcid.org/0000-0003-0045-3571 \\ Janari da Silva Pedroso 3 \\ Dhttps://orcid.org/0000-0001-7602-834X \\ 1,3Programa de Pós-Graduação em Psicologia e Faculdade de Psicologia, Universidade Federal do Pará, Brasil \\ Faculdade de Psicologia, Universidade Federal do Pará, Brasil
}

Resumo. Objetivo. O objetivo foi identificar as contribuições da psicanálise na formulação das práticas de cuidado em saúde mental no Brasil. Método. Utilizou-se o método da revisão integrativa de literatura com metassíntese nas bases de dados PubMed, BVS, LILACS, SciELO, com buscas nos períodos de 2008 a 2018. Resultados. Os resultados indicam que a psicanálise contribuiu com a noção de diagnóstico estrutural, nova perspectiva de cura, trabalho com o delírio e a arte, "prática feita por muitos", construção do caso clínico, clínica ampliada e escuta singular. Conclui-se que a psicanálise faz parte da reestruturação e criação de práticas de cuidado em instituições de saúde mental, no âmbito de dispositivos teóricos e técnicos, para que as especificidades do paciente direcionem o tratamento.

Palavras-chave. Saúde mental, Reforma psiquiátrica, Instituições, Psicanálise, Práticas de cuidado.

Abstract. Objective. The objective is to identify the contributions of psychoanalysis in the formulation of mental health care practices in Brazil. Method. The method of integrative literature review with meta-synthesis was used in the PubMed, BVS, LILACS, SciELO databases, with searches from 2008 to 2018. Results. The results indicate that psychoanalysis contributed to the notion of structural diagnosis, a new perspective of healing, work with delirium and art, "practice made by many" construction of the clinical case, expanded clinic, and unique listening. In conclusion, psychoanalysis is part of the restructuring and creation of care practices in mental health institutions within the scope of theoretical and technical devices, so the patient specificities guide the treatment.

Keywords. Mental Health, Psychiatric Reform, Institutions, Psychoanalysis, Care Practices.

'João Paulo Nogueira da Silva. Programa de Pós-Graduação em Psicologia e Faculdade de Psicologia, Universidade Federal do Pará, Brasil. Direção postal: Rua Augusto Corrêa, 01, Campus Guamá, CEP: 66075-110, Brasil. E-mail: borgesjpsilva@yahoo.com.br ${ }^{2}$ Carolina Ventura Silva. Faculdade de Psicologia, Universidade Federal do Pará, Brasil. E-mail: carolinaventura.psicologia@gmail.com ${ }^{3}$ Janari da Silva Pedroso. Programa de Pós-Graduação em Psicologia e Faculdade de Psicologia, Universidade Federal do Pará, Brasil. E-mail: jsp@ufpa.br

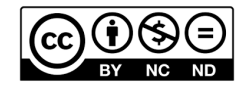

Esta obra está bajo una licencia de Creative Commons Reconocimiento-NoComercial-SinObraDerivada 4.0 Internacional. 


\section{Introdução}

Operacionalizou-se no século XXI o projeto de superação do modelo higienista de saúde, que subsidiou práticas de cuidado a partir de tratamentos que submetiam sujeitos a itinerários de dispositivos técnicos, decorrentes da compreensão biomédica de cura e controle de patologias (Cardoso et al., 2016). Paulatinamente, passou-se a compreender o cuidado em saúde como a relação de saberes entre dois sujeitos ativos no processo saúde/doença: o profissional da saúde e o paciente/usuário (Quintanilha et al., 2017).

O paciente, por meio do conhecimento do profissional da saúde, conhece e aprende sobre sua doença para melhor se cuidar. O profissional compreende que sua atuação no cuidado do paciente o impacta de modo singular, ao identificar sua singularidade no saber e não-saber do seu processo de saúde/doença. Atentar para as especificidades dos pacientes/usuários é a base do Sistema Único de Saúde (SUS) em sua prática de cuidado (Lei 8080, 1990).

O conceito de prática de cuidado varia no tempo e espaço, principalmente no campo da saúde mental, que historicamente esteve fortemente atrelada ao conceito de loucura. Ao analisarmos o percurso histórico da loucura, é possível perceber a mudança do conceito de prática de cuidado, e como esse elemento possibilitou ao Estado organizar as sociedades a partir do final do século XV. Nesse período, o cuidado em saúde mental significava internamento genérico, enquanto a loucura era representada como desorganizadora da sociedade ao subsidiar a improdutividade, que era considerada patologia para o Estado nas revoluções industriais dos séculos XVIII e XIX (Foucault, 1978).

A prática de cuidado oferecida aos ditos loucos, foi a internação nos antigos leprosários. O Estado legitima essa prática de cuidado, quando transforma os antigos leprosários em manicômios (Goffman, 2008). Eram locais onde os ditos loucos residiam por longos períodos em regime fechado e formalmente administrado, para que se enxergassem como mal em si, e aquele local como seu lugar natural. O manicômio e a internação, eram os principais símbolos do lugar e do modo de cuidar desse sujeito, eram o campo da saúde mental e o fenômeno da loucura em simbiose perfeita.

Entende-se que esse modelo de prática de cuidado não era adequado ao tratamento da loucura, e a psiquiatria foi a primeira ciência que desconstituiu essa estrutura de cuidado ao ressignificar a função do isolamento, dando-lhe o status de meio necessário à reinserção do louco na sociedade, após uma série de tratamentos, em detrimento da simples exclusão (Vieira, 2015). Foi uma modificação mínima nas práticas de cuidado anterior, uma vez que, continuava a manter o cuidado em saúde mental segregacionista.

A percepção científica psiquiátrica sobre a loucura foi ambivalente, porque atualizou o gesto negativo da exclusão, com a busca do reajustamento moral do louco, mas, ao mesmo tempo, trouxe o significado positivo de "cura" com a desinternação, por meio da utilização de fármacos (Birman \& Costa, 1994). Essa ambivalência constituiu o paradigma clínico psiquiátrico, a partir da relação causa-desencadeadores-cura da doença (Rotelli, 1990). É nessa ambivalência que surge o saber psicanalítico com a postulação de que o tratamento da loucura não necessitava passar pelo isolamento.

O saber da psicanálise, no campo das práticas de cuidado em saúde mental, se constituiu em desfavor das práticas manicomiais de isolamento em instituições, ao operacionalizarse em subversão à concepção de razão como forma exclusiva de explicação das experiências humanas (Braga, 2017). Formulou-se a teoria do inconsciente (Freud, 
1996/1924), para compreender o funcionamento psíquico dos sujeitos, em oposição à normatividade da razão como hegemônica nas formulações de práticas de cuidado no campo da saúde mental.

A psicanálise diluiu a polarização entre o reducionismo biológico da psiquiatria de remissão do sintoma, com a atenção psicossocial, que subsidiou a reinserção do louco na vida social por meio da autonomia e do trabalho (Tenório et al., 2017). Os psicanalistas atualizaram as ferramentas terapêuticas da clínica privada para a necessidade da saúde coletiva, e com isso reestruturaram as práticas de cuidado em saúde mental, e isto foi favorecido pelo contexto histórico da reforma psiquiátrica que ocorreu em diversos países.

O Brasil pôs-se a superar o manicômio a partir da década de 1960, por: denúncias das condições precárias, os maus-tratos, tratamentos ineficazes, carga-horária excessiva dos técnicos e seus baixos salários, alinhados com a vinda ao país de Franco Basaglia e Erving Goffman (Lüchmann \& Rodrigues, 2007). Articularam-se movimentos em torno de sua extinção, por meio dos trabalhadores da saúde e entidades civis, que culminou no Manifesto de Bauru, o qual teve como lema: "por uma sociedade sem manicômios", em 18 de maio de 1987.

Essa confluência possibilitou a desinstitucionalização de pacientes, quando os serviços de atenção psicossocial realizaram a sua reinserção nos territórios de origem (Ministério da Saúde [MS], 2013). A psicanálise e reforma psiquiátrica reestruturaram a instituição de saúde mental, com serviços abertos de cuidado longitudinal e intensivo para os períodos de crise, que possibilitam as trocas nos territórios.

As instituições de saúde mental passaram a ser operacionalizadas em níveis hierárquicos de atenção: primário, secundário e terciário (MS, 2013). Se converteu a primária na porta de entrada preferencial no acesso ao SUS, que passou a se localizar no território do usuário no âmbito individual e coletivo. O conceito de saúde mental começou a significar práticas de cuidado destinadas à prevenção, promoção e recuperação do bem-estar do sujeito na percepção de suas habilidades para lidar com o estresse cotidiano, o trabalho produtivo e contribuir para sua comunidade (World Health Organization [WHO], 2014).

É latente que as contribuições da psicanálise se inseriram nas instituições de saúde coletiva, como nos Centros de Atenção Psicossocial (CAPS). Identificar essas contribuições evidencia a relevância teórica, prática e social do saber psicanalítico à saúde pública, e, simultaneamente, salienta a necessidade de considerar seus novos conceitos para a manutenção e produção de políticas públicas. Define-se, portanto, como objetivo do estudo: identificar as contribuições da psicanálise às práticas de cuidado em saúde mental no Brasil.

\section{Método}

Delineamento de pesquisa

Realizou-se a revisão integrativa com metassíntese da literatura brasileira, a partir de seis etapas: formulação da questão norteadora, definição dos critérios de inclusão e exclusão, escolha dos descritores, avaliação dos estudos incluídos, interpretação dos resultados e apresentação da revisão (Mendes et al., 2008). Opta-se pela metassíntese, para abranger pesquisas quantitativas e qualitativas, o que não seria possível se a interpretação fosse feita com meta-análise, pois só inclui estudos quantitativos (Urra Medina \& Barría Pailaquilén, 2010). 


\section{Procedimentos}

A pergunta norteadora foi: quais as contribuições da psicanálise ao cuidado em saúde mental? Utilizou-se as bases de dados PubMed, BVS, LILACS, e SciELO, selecionadas por serem de acesso gratuito. A lista de descritores da BVS-Psi foi consultada e os termos considerados adequados ao objetivo desta pesquisa foram: loucura; reforma psiquiátrica; instituições; psicanálise; práticas de cuidado.

Os descritores em português utilizados com o booleano (AND) foram: "psicanálise AND loucura AND práticas de cuidado"; "psicanálise AND instituições AND reforma psiquiátrica"; "práticas de cuidado AND instituições AND reforma psiquiátrica"; "reforma psiquiátrica AND loucura".

Os critérios de inclusão consistiram na seleção de artigos publicados em revistas de Qualis A1 a B2 avaliadas pela Coordenação de Aperfeiçoamento de Pessoal de Nível Superior (CAPES, Brasil), pelo rigor na revisão às cegas (double bind), redigidos em português; com publicação no período 2008 a 2018 (referentes a dois ciclos de atualização). Artigos que respondessem à pergunta norteadora a partir da metodologia $\mathrm{PICo}$, que é o acrônimo de População (usuários de instituições de saúde mental), Interesse (práticas de cuidado), Contexto (revisão e/ou empírico) e "Outcomes" (Resultado) (contribuição psicanalítica), de pesquisa não-clínica (Santos et al., 2007).

Ao se utilizar a combinação dos descritores, foram encontrados nas bases de dados 429 artigos, 130 não se enquadraram nos critérios de idioma, formato artigo, pesquisa nacional e ano, o que reduziu a amostra para 299; desse total 241 estavam repetidos. Restaram 58 artigos, 10 foram excluídos por não terem Qualis de A1 a B2, na verificação da Plataforma Sucupira na área de psicologia e saúde coletiva do quadriênio avaliação 2013-2016 da CAPES, restaram 48.

Submeteu-se os 48 artigos à avaliação PICo, dois juízes realizaram triagens independentes, com margem de discordância de 10\%, o que corresponde a um item, acima desse percentual excluía-se o artigo. Foram excluídos 8 artigos por discordância dos juízes. Excluiu-se 2 por ausência de "P", 5 por ausência de "I" e 12 por ausência de "Co". Restaram 21 artigos, que compuseram a pesquisa, que se denominou de corpus analítico. A Figura 1 representa o procedimento de seleção, análise e composição da amostra.

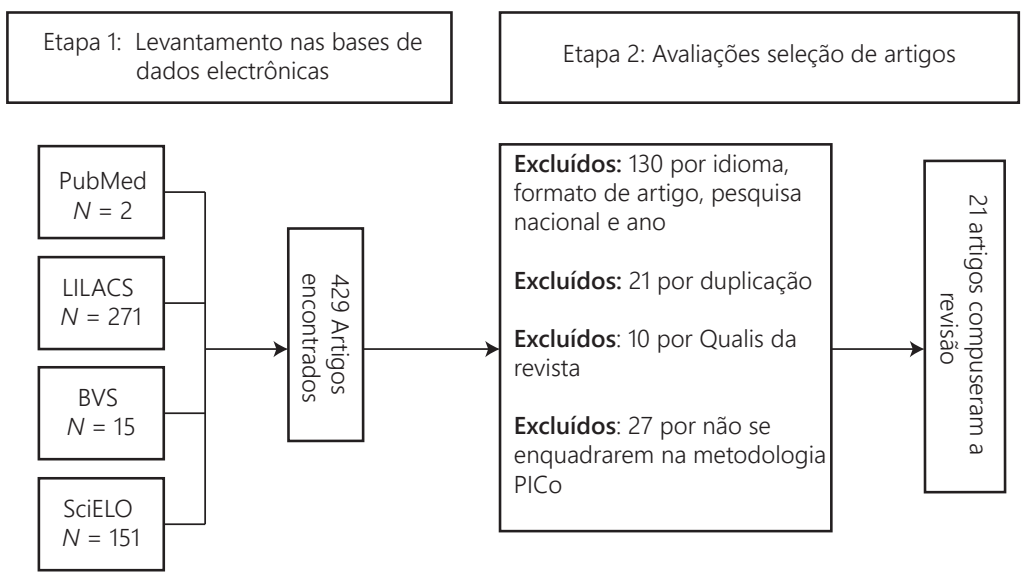

Figura 1. Fluxograma com os registros encontrados, artigos selecionados para leitura, análise e discussão. 


\section{Resultados}

O corpus analítico foi novamente lido na íntegra para obtenção dos principais dados dos artigos. Oito artigos eram oriundos de estudos empíricos de profissionais que atuam em instituições de saúde mental, que corresponde a $40 \%$ da amostra, e os outros treze, $60 \%$, eram clínico-teóricos de profissionais acadêmicos que já tinham atuado nesses espaços, e todos realizaram análises qualitativas. Destaca-se que o ano de 2008 teve o maior número de publicações, com 8 artigos.

Na sistematização dos dados se utilizou a síntese temática de Thomas e Harden (2008). Os artigos foram numerados ordinalmente a partir das semelhanças de resultados. Os quatros primeiros artigos apresentaram as contribuições teóricas e práticas da psicanálise ao movimento de reforma psiquiátrica brasileira, como a questão do tratamento (Travaglia, 2014), especificidade da psicanálise na prática de cuidado (Junior \& Besset, 2012), psicanálise e assistência pública (Dassoler \& Palma, 2011) e atualização do individual ao coletivo clínico (Alberti, 2008). Formaram a categoria 1: "Psicanálise e Reforma Psiquiátrica"

Do artigo cinco a onze, apresentaram a psicanálise operacionalizada nas práticas de cuidado. Destaca-se a função do psicanalista na saúde mental (Carneiro, 2008), ética psicanalítica na atuação psicossocial (Costa-Rosa, 2011), psicanálise no cuidado do CAPS (Quadros et al., 2018), clínica da psicose (Monteiro et al., 2016), psicanálise na prática de cuidado de outros saberes presentes no CAPS (Vilhena \& Rosa, 2011), prática de desinserção (Generoso \& Guerra, 2012) e prática de suporte de habitação e inserção social (Guerra \& Generoso, 2009). Formaram a categoria 2: "Psicanálise e Práticas de Cuidado".

Os artigos de doze a dezoito, descrevem a psicanálise no contexto de instituições públicas de cuidado coletivo. Destaca-se a prática entre vários (Abreu, 2008), a prática clínica em instituições públicas (Rinaldi, 2015), o método da construção do caso clínico psicanalítico na instituição (Palombini \& Rocha, 2017), a psicoterapia psicanalítica de grupo na instituição (Campos et al., 2010), estratégia de cuidado na psicose na instituição (Muñoz, 2010), o discurso do analista na instituição (Pena, 2017) e os procedimentos clínicos psicoanalíticos realizados no CAPS (Rinaldi \& Burszty, 2008). Formaram a categoria 3: "Psicanálise e Instituição de Saúde Mental".

Os artigos de dezenove a vinte e um, apresentaram a atualização da clínica psicanalítica a dimensão ampliada a coletivos. Destaca-se a função do trabalho psicanalítico nos Serviços Residenciais Terapêuticos (Figueiredo \& Frare, 2008), discussões com outros saberes na implementação da clínica ampliada (Rabêlo et al., 2018) e clínica e reforma psiquiátrica (Couto \& Alberti, 2008). Formaram a categoria 4: "Psicanálise e Clínica: Clínica Ampliada e Escuta Singular".

Por fim, utilizou-se as categorias descritivas para responder à questão da revisão ao torná-las eixos de discussão. A Tabela 1 apresenta a caracterização do corpus analítico com título, objetivo, autor, ano de publicação, e Qualis, divididos em eixo 1, 2, 3 e 4. 
Tabela 1

Artigos organizados por eixos temáticos

\begin{tabular}{|c|c|c|c|c|}
\hline Título & Objetivo & Autor & Ano & Qualis \\
\hline \multicolumn{5}{|l|}{ Eixo 1: Psicanálise e reforma psiquiátrica } \\
\hline $\begin{array}{l}\text { Psicanálise e saúde mental, uma visão } \\
\text { crítica sobre psicopatologia contem- } \\
\text { porânea e a questão dos diagnósticos }\end{array}$ & $\begin{array}{l}\text { Compreender como os } \\
\text { sujeitos são tratados a partir } \\
\text { do diagnóstico. }\end{array}$ & Travaglia & 2014 & B2 \\
\hline $\begin{array}{l}\text { Contribuição ao debate entre } \\
\text { a psicanálise e a atual reforma } \\
\text { psiquiátrica brasileira }\end{array}$ & $\begin{array}{l}\text { Analisar a influência do } \\
\text { discurso do psicanalista na } \\
\text { reforma psiquiátrica a partir } \\
\text { da clínica. }\end{array}$ & Couto e Alberti & 2008 & B1 \\
\hline $\begin{array}{l}\text { Psicanálise e saúde mental: Contextu- } \\
\text { alizando o atendimento às demandas }\end{array}$ & $\begin{array}{l}\text { Evidenciar a especificidade } \\
\text { da psicanálise na construção } \\
\text { de práticas de cuidado. }\end{array}$ & Junior e Besset & 2012 & $\mathrm{~A} 2$ \\
\hline $\begin{array}{l}\text { Contribuições da Psicanálise para a } \\
\text { Clínica Psicossocial }\end{array}$ & $\begin{array}{l}\text { Analisar saberes e práticas } \\
\text { que contribuíram na as- } \\
\text { sistência mental pública. }\end{array}$ & $\begin{array}{l}\text { Dassoler e } \\
\text { Palma }\end{array}$ & 2011 & B1 \\
\hline $\begin{array}{l}\text { A política da psicanálise e a da saúde } \\
\text { mental }\end{array}$ & $\begin{array}{l}\text { Analisar a psicanálise na di- } \\
\text { mensão individual e coletiva. }\end{array}$ & Alberti & 2008 & $\mathrm{~A} 2$ \\
\hline \multicolumn{5}{|l|}{ Eixo 2: Psicanálise e práticas de cuidado } \\
\hline $\begin{array}{l}\text { Do modelo asilar-manicomial ao } \\
\text { modelo de reabilitação psicossocial } \\
\text { - haverá um lugar para o psicanalista } \\
\text { em Saúde Mental? }\end{array}$ & $\begin{array}{l}\text { Analisar o lugar do psicana- } \\
\text { lista na clínica da psicose. }\end{array}$ & Carneiro & 2008 & $\mathrm{~A} 2$ \\
\hline $\begin{array}{l}\text { Ética e Clínica na Atenção Psicossocial: } \\
\text { contribuições da psicanálise de Freud } \\
\text { e Lacan }\end{array}$ & $\begin{array}{l}\text { Discutir a ética da atenção } \\
\text { psicossocial da saúde mental } \\
\text { coletiva. }\end{array}$ & Costa-Rosa & 2011 & B2 \\
\hline $\begin{array}{l}\text { Psicanálise e saúde mental: um estudo } \\
\text { sobre o estado da arte }\end{array}$ & $\begin{array}{l}\text { Analisar o estado da arte da } \\
\text { Psicanálise e a saúde mental } \\
\text { na prática clínica do CAPS. }\end{array}$ & Quadros et al. & 2018 & B1 \\
\hline $\begin{array}{l}\text { Soluções psicóticas e intervenções } \\
\text { analíticas }\end{array}$ & $\begin{array}{l}\text { Abordar a especificidade da } \\
\text { clínica da psicose a partir do } \\
\text { referencial da psicanálise de } \\
\text { orientação lacaniana. }\end{array}$ & Monteiro et al. & 2016 & B2 \\
\hline $\begin{array}{l}\text { A clínica psicanalítica nos espaços } \\
\text { abertos do CAPS }\end{array}$ & $\begin{array}{l}\text { Analisar a relação da } \\
\text { psicanálise com os demais } \\
\text { saberes no CAPS. }\end{array}$ & Vilhena e Rosa & 2011 & $\mathrm{~A} 2$ \\
\hline $\begin{array}{l}\text { Desinserção social e habitação: a } \\
\text { psicanálise na reforma psiquiátrica } \\
\text { brasileira }\end{array}$ & $\begin{array}{l}\text { Analisar a prática da des- } \\
\text { inserção da psicanálise na } \\
\text { reforma psiquiátrica. }\end{array}$ & $\begin{array}{l}\text { Generoso e } \\
\text { Guerra }\end{array}$ & 2012 & $\mathrm{~A} 2$ \\
\hline $\begin{array}{l}\text { Inserção social e habitação: modos } \\
\text { dos portadores de transtornos men- } \\
\text { tais habitarem a vida na perspectiva } \\
\text { psicanalítica }\end{array}$ & $\begin{array}{l}\text { Avaliar habitação e inserção } \\
\text { social a partir do suporte } \\
\text { social. }\end{array}$ & $\begin{array}{l}\text { Guerra e } \\
\text { Generoso }\end{array}$ & 2009 & $\mathrm{~A} 2$ \\
\hline
\end{tabular}

Continue...

Actualidades en Psicología, 35(130), 2021, 19-34 


\begin{tabular}{|c|c|c|c|c|}
\hline Título & Objetivo & Autor & Ano & Qualis \\
\hline \multicolumn{5}{|c|}{ Eixo 3: Psicanálise e instituição de saúde mental } \\
\hline $\begin{array}{l}\text { A prática entre vários: a psicanálise } \\
\text { na instituição de saúde mental }\end{array}$ & $\begin{array}{l}\text { Discutir a psicanálise na instituição } \\
\text { no tratamento da loucura. }\end{array}$ & Abreu & 2008 & B1 \\
\hline $\begin{array}{l}\text { Micropolítica do desejo: a clínica } \\
\text { do sujeito na instituição de saúde } \\
\text { mental }\end{array}$ & $\begin{array}{l}\text { Discutir questões da prática clínica } \\
\text { em instituições públicas, a partir } \\
\text { da prática "entre vários". }\end{array}$ & Rinaldi & 2015 & B1 \\
\hline $\begin{array}{l}\text { A clínica do acompanhamen- } \\
\text { to terapêutico como pesquisa } \\
\text { psicanalítica: uma escrita com- } \\
\text { partilhada entre vários }\end{array}$ & $\begin{array}{l}\text { Discutir o caso clínico a partir do } \\
\text { Acompanhamento Terapêutico à } \\
\text { clínica psicanalítica. }\end{array}$ & $\begin{array}{l}\text { Palombini e } \\
\text { Rocha }\end{array}$ & 2017 & $\mathrm{~A} 2$ \\
\hline $\begin{array}{l}\text { A Confusão de Línguas e os De- } \\
\text { safios da Psicanálise de Grupo em } \\
\text { Instituição }\end{array}$ & $\begin{array}{l}\text { Discutir o modelo de psicoterapia } \\
\text { psicanalítica de grupo em institu- } \\
\text { ição pública. }\end{array}$ & Campos et al. & 2010 & $\mathrm{~A} 2$ \\
\hline $\begin{array}{l}\text { Do amor à amizade na psicose: } \\
\text { contribuições da psicanálise ao } \\
\text { campo da saúde mental }\end{array}$ & $\begin{array}{l}\text { Analisar a noção de amor e ami- } \\
\text { zade na estratégia de práticas de } \\
\text { cuidado. }\end{array}$ & Muñoz & 2010 & $\mathrm{~A} 2$ \\
\hline $\begin{array}{l}\text { A construção do caso em saúde } \\
\text { mental como meio de sustentar o } \\
\text { discurso do analista na instituição }\end{array}$ & $\begin{array}{l}\text { Demonstrar a presença do discur- } \\
\text { so do analista na instituição. }\end{array}$ & Pena & 2017 & B2 \\
\hline $\begin{array}{l}\text { O desafio da clínica na atenção } \\
\text { psicossocial }\end{array}$ & $\begin{array}{l}\text { Discutir os procedimentos clínicos } \\
\text { que se realizam no CAPS. }\end{array}$ & $\begin{array}{l}\text { Rinaldi e } \\
\text { Burszty }\end{array}$ & 2008 & $\mathrm{~A} 2$ \\
\hline \multicolumn{5}{|l|}{ Eixo 4: Psicanálise e clínica } \\
\hline $\begin{array}{l}\text { A função da psicanálise e o tra- } \\
\text { balho do psicanalista nos Serviços } \\
\text { Residenciais Terapêuticos (SRT) }\end{array}$ & $\begin{array}{l}\text { Analisar os SRT e a reforma } \\
\text { psiquiátrica no Brasil. }\end{array}$ & $\begin{array}{l}\text { Figueiredoe } \\
\text { Frare }\end{array}$ & 2008 & $\mathrm{~A} 2$ \\
\hline $\begin{array}{l}\text { Esquizofrenia, clínica e saúde } \\
\text { mental na psicologia sócio- } \\
\text { histórica e na psicanálise }\end{array}$ & $\begin{array}{l}\text { Discutir a relação da psicologia } \\
\text { sócio-histórica com a psicanálise } \\
\text { na clínica ampliada. }\end{array}$ & Rabêlo et al. & 2018 & $\mathrm{~A} 2$ \\
\hline $\begin{array}{l}\text { Contribuição ao debate entre } \\
\text { a psicanálise e a atual reforma } \\
\text { psiquiátrica brasileira }\end{array}$ & $\begin{array}{l}\text { Analisar a influência do discurso } \\
\text { do psicanalista na clínica ampliada. }\end{array}$ & $\begin{array}{l}\text { Couto e } \\
\text { Alberti }\end{array}$ & 2008 & B1 \\
\hline
\end{tabular}

\section{Discussão}

\section{Psicanálise e reforma psiquiátrica}

A análise conjunto dos resultados da categoria 1, consolidou duas principais contribuições da psicanálise ao movimento de reforma psiquiátrica brasileira, que são: o diagnóstico estrutural e a noção de cura. Devido à realidade psíquica ser fundamental para se compreender o funcionamento do sujeito e a impossibilidade de acessá-la diretamente, houve a necessidade de reformulação do diagnóstico clínico biomédico, para que não se tomasse o sintoma como o próprio fenômeno da doença (Figueiredo \& Machado, 2000).

A noção de diagnóstico estrutural, compreende o sintoma apenas como indicador da estrutura de funcionamento particular do sujeito (Figueiredo \& Machado, 2000). O diagnóstico deixa de ser exclusivamente a descrição objetiva para operar a identificação da estrutura psíquica de funcionamento do paciente. A psicanálise não opera sua ação na simples classificação do sujeito no rol dos diagnosticados com patologia, mas por meio de estruturas clínicas fundamentais de funcionamento do sujeito, como psicose, neurose e perversão, que o torna singular na realização da prática de cuidado (Oliveira \& Neves, 2012; Junior \& Besset, 2012; Dassoler \& Palma, 2011). 
As categorias diagnósticas clássicas da psiquiatria perderam sua hegemonia nas formulações de compressões sobre a loucura, que forçou a renovação da clínica psiquiátrica. Ela passou a operar fortemente a doença mental na dimensão subjetiva, o sujeito como foco da produção de verdade singular com sua história única, independente de qual estrutura psíquica possua (Figueiredo \& Tenório, 2002; Oliveira \& Neves, 2012). A psicanálise ajudou a construir a noção de cura diferenciada, segunda contribuição, que se opõe à hegemonia da remissão de sintomas pela medicalização.

A noção de cura parte da articulação freudiana de corpo e psique, por meio de representações e sentidos, na qual a realidade do psiquismo abrange processos conscientes e inconscientes na produção do sintoma (Perón \& Dunker, 2002). O sintoma se reveste de sentido ao ser preenchido pela história particular do sujeito. Não mais compreendido como estado negativo de condições objetivas, que podem ser remidas para o desaparecimento total da doença (Peron \& Dunker, 2002). Essa noção de cura dá-se no momento em que o sujeito consegue viver melhor, o que não se resume no conceito de resultado, mas sim no processo de elaboração (Freud, 1996/1937).

Essa perspectiva de cura questiona o modelo linear de sinais-diagnóstico-tratamentocura, que se fundava na remissão dos sintomas exclusivamente pelos aspectos biológicos. Na reforma psiquiátrica, essa noção de cura é apropriada pelas novas concepções de cuidado em saúde mental que desconstituíram práticas de rotulação por diagnóstico e medicalização dos sujeitos na pressa de curá-los, o que se opõe ao processo de elaboração psíquica (Alberti, 2008). Há possibilidades de acompanhamento terapêutico dos pacientes com atenção às suas singularidades, o que é fundamental na formulação de seu tratamento, pois evita práticas ineficazes para a melhora de seu quadro clínico, como o isolamento genérico.

\section{Psicanálise e práticas de cuidado}

Já a análise dos resultados da categoria 2, fez surgir duas principais contribuições da psicanálise operacionalizada nas práticas de cuidado, que são: o trabalho com o delírio e a arte (Quadros et al., 2018; Monteiro et al., 2016). Esses dois dispositivos são formas de cura por meio da reconstrução da realidade, que podem promover o advento do sujeito da loucura (Guerra, 2010). A reconstrução ocorre a partir da reorganização subjetiva, ou seja, estabilização que permite o sujeito fazer laço social a partir da simbolização dos significados.

A reorganização subjetiva se dá à medida que o delírio compensa as perdas e/ou ausências de processos psíquicos fundamentais à constituição do sujeito, como a castração e foraclusão, que resultaram no fracasso das relações no mundo exterior e o afasta de parte da realidade (Quinet, 2006). A compensação psíquica ocorre quando o delírio se torna a metáfora delirante, a qual consiste na busca de explicação para os fenômenos que o invadem, e essa certeza delirante é o saber fundamental que foi adquirido para a construção da nova realidade (Guerra, 2010).

O delírio é a principal via de acesso da psicanálise às psicoses, que por meio da metáfora delirante possibilita as significações à medida em que significante e significado se estabilizam (de Melo e Sousa, 2011). O delírio, enquanto movimento em direção a noção de cura, é a possibilidade de comunicação da subjetividade do paciente e a aproximação da compreensão da função do sintoma (Ribeiro, 2005). A construção do delírio ao longo do tratamento favorece ao psicótico a construir-se como sujeito vinculado a sua história, e movimentar-se e posicionar-se frente aos outros de sua coletividade (Ribeiro, 2005). 
À medida em que o delírio começa a favorecer a passagem ao ato, busca-se diminuir sua potência, por meio da trivialização (Rinaldi, 2006). A trivialização consiste em realizar simples intervenções em momentos críticos da demanda psicótica, em que o profissional se utiliza do vínculo para iniciar conversas sobre assuntos comuns da vida do paciente, em detrimento de incentivar as suas construções elaboradas do delírio, para que este perca força e se esvazie de sentido, e, logo, de gozo (de Melo e Sousa, 2011).

O trabalho com a arte consolidou-se largamente na saúde mental, principalmente em relação a pacientes graves com quadros de dificuldade extrema em fazer laço social por meio da fala (Vilhena \& Rosa, 2011). A produção artística promove a estabilização psicótica ao mediar o encontro analítico, a interpretação e intervenção na arte, e ao assumir o papel do analista (Generoso \& Guerra, 2012; Guerra \& Generoso, 2009). Isso é possível devido a produção artística sustentar o sujeito na construção de formas de lidar com a foraclusão, o que a torna essencial nos dispositivos substitutivos (de Melo e Sousa, 2011).

A presença do analista em oficinas artísticas promove a articulação entre o fazer criativo e a emergência de produção subjetiva, atentos aos modos de expressão (de Melo e Sousa, 2011). Compreende-se que a psicanálise é aplicada na arte, para que esta possa ser absorvida na instituição de saúde mental, e tenha subsídio para sustentar o sujeito no contorno das falhas dos processos psíquicos (Autuori, 2005). O trabalho artístico promove o laço social entre quem ocupa a função de analista e o de sujeito, não está relacionado à produção de obras de arte, valorizadas pela sociedade, e pode até mesmo inexistir objeto ao final do trabalho (de Melo e Sousa, 2011).

Psicanálise e instituição de saúde mental

A categoria 3, que tratou da psicanálise no contexto de instituições públicas de cuidado coletivo em saúde mental com equipes multidisciplinares, sintetiza duas contribuições psicanalíticas: "prática feita por muitos" e construção do caso (Benetti \& Cunha, 2008; Rinaldi \& Bursztyn, 2008). O termo "prática feita por muitos" é decorrente da expressão "pratique à plusieurs" concebida por Jacques-Alain Miller, quem se referia à prática que acontece nas instituições de saúde mental que envolve vários profissionais em torno de cada caso (Di Ciaccia, 1998). Faz referência à multiplicidade de discursos que puderam funcionar articulados nas instituições, na década de 70 (Laurent, 1999).

A articulação dá-se quando a psicanálise começa a se inserir na reestruturação dos serviços substitutivos em equipes multiprofissionais (Elia, 2000). Contudo, mesmo que se esteja no âmbito de equipe multiprofissional, não se resume a trabalho em grupo (Abreu, 2008). Não se formam aglomerados de sujeitos para serem atendidos, mas a equipe volta-se a atender um a um, para se afastar das generalizações da psiquiatria clássica (Palombini \& Rocha, 2017). A especificidade dessa prática está em seus quatro eixos que a orientam: a desespecialização, a formação, a invenção e a transmissão (Stevens, 2007).

A desespecialização é a ação voltada a evitar a identificação monossintomática - enquadramento exclusivo do sintoma a categoria patológica hegemônica - e a concepção do pressuposto do profissional especialista (Stevens, 2007). Despersonalizase a medida em que se necessita constituir a prática de cuidado com os saberes de todos os profissionais. Não se trata de cada um trabalhar somente em sua especialidade, mas pelo saber construído a partir de cada paciente, que perpassa todas as especialidades (Abreu, 2008).

No eixo da formação, dá-se importância ao contato com os pressupostos teóricos da psicanálise. Contudo, não há necessidade de que todos os profissionais sejam psicanalistas, 
mas todos devem fazer transferência com esse saber e estar em processo de análise (Stevens, 2007). O eixo da invenção se direciona tanto ao sujeito do tratamento quanto aos membros da equipe. Estes devem estar sempre atentos à invenção e à surpresa produzida pelos sujeitos, pois considera-se que a instituição deve caber ao paciente e não o contrário (Muñoz, 2010).

A transmissão é o eixo central na equipe, e ocorre por meio das reuniões dos profissionais (Stevens, 2007). Na reunião da equipe, intervenções são discutidas e avaliadas, pois nem toda invenção do sujeito é sustentada, mas apenas as que proporcionem o ponto estabilizador ao sujeito para poder localizar seu desejo. A transmissão de diversos saberes teóricos entre si só se torna possível à medida que compreendem, de antemão, que não se sabe nada sobre o paciente, mas constrói-se saber a partir deste. Cada profissional se autoriza e, põe-se a operar e construir sua prática de cuidado a partir da especificidade de cada sujeito (Baio,1999).

Deriva-se do eixo da transmissão a construção do caso clínico, a segunda contribuição no âmbito de instituições multiprofissionais (Figueiredo, 2004; Campos et al., 2010). A discussão dos casos clínicos constitui importante ferramenta de formação e avaliação do aprimoramento do tratamento, pois a gama de conhecimento em saúde mental tornou possível e necessária o debate aberto entre os profissionais (Viganò, 2010). Isso implica na inversão da posição de saber, na qual o paciente tem algo a ensinar à instituição de atendimento, a partir das suas narrativas sobre sua doença, que não necessariamente localizam-se no prisma da razão (Rabêlo et al., 2018).

A construção do caso clínico opera no recolhimento da experiência do sujeito, por meio do seu discurso, com objetivo de direcionar ações e intervenções da equipe (Figueiredo, 2004). Possibilita-se a escuta clínica de toda a equipe envolvida nas práticas de cuidado e a melhor estruturação do tratamento (Pena, 2017). É essa perspectiva que afasta a concepção de saber hegemônico proposta pela psiquiatria clássica, pois a lógica da construção do caso clínico perpassa pela dinâmica democrática, a qual desconsidera as proposições de hierarquias de saberes e possibilita o predomínio da escuta da singularidade da história do paciente.

\section{Psicanálise e clínica}

Da categoria 4, pode-se identificar duas principais contribuições da psicanálise, que são: a clínica ampliada e a escuta singular. O setting terapêutico freudiano, onde o sujeito fala livremente, facilitou a ampliação da clínica psiquiátrica, que era hermética em suas categorias diagnósticas clássicas (Figueiredo \& Frare, 2008). A psicanálise colabora nesse sentido para a construção da noção de clínica ampliada, que toma a subjetividade como elemento central, e se põe "em movimento" ao articular-se constantemente com a dinâmica cultural, composta pela vida e sociedade, em que o sujeito da loucura se localiza (Lobosque, 2003).

Os conceitos pós-freudianos, como foraclusão, a contextualização conceitual e a relocalização da prática, trouxeram condições necessárias à superação da concepção de restrição da psicanálise ao campo das neuroses (de Melo e Sousa, 2011). Supera-se o imaginário de que a psicanálise não teria arcabouço para as demandas de instituições que atendessem os coletivos. A sua inserção ainda é questionada, porém a sua prática é utilizada em diversos quadros psicopatológicos como dispositivo substitutivo em saúde mental no Brasil (Monteiro \& Queiroz, 2006; Rabêlo et al., 2018).

Com a psicanálise, a internação deixa de ser o único meio de tratamento, e torna-se mecanismo apenas eventual (Tenório, 2001). A clínica ampliada, nos serviços substitutivos 
em saúde mental, torna mais intercambiável os limites entre os espaços de cuidado dos indivíduos em sofrimento psíquico e a sociedade (de Melo e Sousa, 2011). A clínica ampliada insere-se no intenso fluxo de usuários e constantes intercorrências, intrínsecos a realidade das instituições de saúde mental. Admite-se e suporta-se esse contexto em função das intervenções serem construídas em diversos lugares, como corredores ou sentados no banco do jardim da instituição (de Melo e Sousa, 2011).

A clínica ampliada, ao realizar a escuta singular na instituição de saúde mental, parte da premissa de considerar o louco indivíduo capaz de ter voz e de dizer algo sobre si que não precisa estar dentro da lógica da consciência (Guerra \& Vieira e Souza, 2006). O seu discurso é dotado de sentido que pode ser captado pelo analista, quando aposta na subjetividade deste para a construção da forma de tratamento (Ribeiro, 2005). Privilegiase o acolhimento em detrimento da contenção e medicalização, devido a sua concepção ética de que quem adoece é um sujeito e não somente um corpo (Figueiredo, 1997).

A reflexão crítica da psicanálise sobre sua própria prática de cuidado contribuiu para a continuidade da atividade clínica de tratamento da loucura desvinculada do modelo das grandes patologias psiquiátricas, ao retomar suas descrições nosográficas (Carneiro, 2008). A ruptura epistemológica da psiquiatria com a psicanálise se dá quando esta fórmula a clínica do sujeito situada na ética do desejo, ou seja, a prática de cuidado que se constitui não mais no suposto saber médico, mas a partir do discurso do paciente na sua tentativa de lidar com seus sintomas, angústias e sofrimentos. O analista, o secretário do alienado (Lacan, 2009), é quem direciona o tratamento (Costa-Rosa, 2011; Delgado, 2008).

O analista põe-se em posição de legitimar a subjetividade do outro, o que implica predominantemente na possibilidade de do psicótico expressar sua construção delirante essencial à construção do laço social (de Melo e Sousa, 2011). Elimina-se as generalizações psiquiátricas dos casos, para fins de subsídios de tratamento clínico, e o analista assume a função de sinalizar as vantagens da particularização (Ribeiro, 2005; de Melo e Sousa, 2011). A fala torna-se a ferramenta mais importante nas práticas de cuidado das instituições de saúde mental, pois ocupa lugar particular na linguagem, a qual é fundamental ao trabalho psicanalítico, em detrimento do divã ou número mínimo de sessões por semana (Goidanich, 2001).

A revisão integrativa possibilitou identificar e analisar as contribuições da psicanálise nas práticas de cuidado em saúde mental. Destacou-se a noção de diagnóstico estrutural, nova perspectiva de cura, trabalho com o delírio e a arte, prática feita por muitos, construção do caso clínico, escuta singular e a aposta na ética do desejo, como os pilares da atuação psicanalítica nas instituições de saúde mental após a reforma psiquiátrica.

O resultado da revisão foi útil para a construção de um quadro referencial aos futuros profissionais de saúde, no qual se evidencia as principais atividades da psicanálise e funções do analista na instituição de saúde mental, para melhor subsidiar as suas práticas nesses serviços. Ademais, permite indicar os atuais limites e possibilidades da psicanálise ao se trabalhar em coletivos, equipe multiprofissionais e políticas públicas sem perder seus principais fundamentos teóricos freudianos.

As principais limitações do estudo referem-se à realização da análise de artigos que apenas tratam das instituições públicas de saúde mental. É importante desenvolver novas pesquisas que busquem estabelecer parâmetros para se analisar a eficácia da contribuição da psicanálise às práticas de cuidado nas instituições de saúde mental, para melhor subsidiar investimentos estatais nesse contexto. 


\section{Referências}

Abreu, D. N. (2008). A prática entre vários: a psicanálise na instituição de saúde mental. Estudos e Pesquisas em Psicologia, 8(1), 74-82. https://doi.org/10.1590/1807-57622016.0477

Alberti, S. (2008). A política da psicanálise e a da saúde mental. Estudos e Pesquisas em Psicologia, 8(1), 7-11.

Autuori, S. (2005). Clínica com arte: considerações sobre a arte na psicanálise [Dissertação de Mestrado não publicada]. Universidade do Estado do Rio de Janeiro.

Baio, V. (1999). O ato a partir de muitos. Curinga Psicanálise e saúde mental, 1(13), 55-62.

Benetti, S., \& Cunha, T. R. S. (2008). Abandono de tratamento psicoterápico: implicações para a prática clínica. Arquivos Brasileiros de Psicologia, 60(2), 48-59.

Birman, J., \& Costa, J. (1994). Organização de Instituições para uma Psiquiatria Comunitária. Em P. A. Amarante, Psiquiatria Social e Reforma Psiquiátrica (pp. 41-72). Fiocruz.

Braga, C. (2017). Conexões na transformação da experiência do sofrimento psíquico: articulação entre memória e história. Interface - Comunicação, Saúde, Educação, 21(63), 823-832. https://doi.org/10.1590/1807-57622016.0477

Campos, D. T. F., Campos, P. H. F., \& Rosa, C. M. (2010). A confusão de línguas e os desafios da psicanálise de grupo em instituição. Psicologia: ciência e profissão, 30(3), 504523. https://doi.org/10.1590/S141498932010000300006

Cardoso, M. R. de O., Oliveira, P. de T. R., \& Piani, P. P. (2016). Práticas de cuidado em saúde mental na voz dos usuários de um Centro de Atenção Psicossocial do estado do Pará. Saúde em Debate, 40(109), 86-99. https://doi.org/10.1590/0103-1104201610907

Carneiro, N. G. de O. (2008). Do modelo asilar-manicomial ao modelo de reabilitação psicossocial: haverá um lugar para o psicanalista em Saúde Mental? Revista Latinoamericana de Psicopatologia Fundamental, 11(2), 208-220. https://doi. org/10.1590/S1415-47142008000200003

Costa-Rosa, A. (2011). Ética e clínica na atenção psicossocial: contribuições da psicanálise de Freud e Lacan. Saúde e Sociedade, 20(3), 743-757. https://doi.org/10.1590/ S0104-12902011000300018

Couto, R., \& Alberti, S. (2008). Contribuição ao debate entre a psicanálise e a atual reforma psiquiátrica brasileira. Mental, 6(11), 15-33. http://pepsic.bvsalud.org/pdf/mental/ v6n11/v6n11a02.pdf

Dassoler, V. A., \& Palma, C. M. de S. (2011). Contribuições da psicanálise para a clínica psicossocial. Revista Mal Estar e Subjetividade, 11(3), 1161-1188. http://pepsic.bvsalud. org/scielo.php?script=sci_arttext\&pid=S1518-61482011001300011\&lng=pt\&tlng=pt

Delgado, S. M. (2008). A dimensão ética da psicanálise na clínica da atenção psicossocial. Estudos e Pesquisas em Psicologia, 8(1), 58-66. http://pepsic.bvsalud.org/scielo. php?script=sci_arttext\&pid=S1679-44272008000200002\&lng=pt\&tlng=pt

De Melo e Sousa, P. S. (2011). A inserção da psicanálise na saúde mental da reforma psiquiátrica brasileira: possibilidades e desafios [Dissertação de Mestrado, Universidade de Brasília]. Repositório Institucional da UnB. https://repositorio. unb.br/handle/10482/6501 
Di Ciaccia, A. (1998). De la fondation par Un à la pratique à plusieurs. Préliminair, 9(10), 17-24.

Elia, L. (2000). Psicanálise: clínica \& pesquisa. Em S. Alberti., \& L. Elia (Orgs.), Clínica e pesquisa em psicanálise (pp. 19-35). Rios Ambiciosos.

Figueiredo, A. C. (1997). Vastas confusões e atendimentos imperfeitos: a clínica psicanalítica no ambulatório público. Relume-Dumará.

Figueiredo, A. C. (2004). A construção do caso clínico: uma contribuição da psicanálise à psicopatologia e à saúde mental. Revista Latinoamericana de Psicopatología Fundamental, 7(1), 75-86. https://doi.org/10.1590/1415-47142004001006

Figueiredo, A. C., \& Frare, A. P. (2008). A função da psicanálise e o trabalho do psicanalista nos serviços residenciais terapêuticos. Revista Latinoamericana de Psicopatología Fundamental, 11(1), 82-96. https://doi.org/10.1590/S1415-47142008000100008

Figueiredo, A. C., \& Machado, O. M. R. (2000). O diagnóstico em psicanálise: do fenômeno à estrutura. Agora: Estudos em Teoria Psicanalítica, 3(2), 65-86. https://doi. org/10.1590/S1516-14982000000200004

Figueiredo, A. C., \& Tenório, F. (2002). O diagnóstico em psiquiatria e psicanálise. Revista Latinoamericana de Psicopatología Fundamental, 5(1), 29-43. https://doi. org/10.1590/1415-47142002001004

Foucault, M. (1978). A história da loucura na idade clássica. Perspectiva.

Freud, S. (1996). A perda da realidade na neurose e na psicose. (J. Salomão, trans.; vol. 19.). Edição standard brasileira das obras psicológicas completas de Sigmund Freud (pp. 203-212). Imago. (Original publicado em 1924).

Freud, S. (1996). Análise terminável e interminável. (J. Salomão, trans.; vol. 23.). Edição standard brasileira das obras psicológicas completas de Sigmund Freud (pp. 225274). Imago. (Original publicado em 1937).

Generoso, C. M., \& Guerra, A. M. C. (2012). Desinserção social e habitação: a psicanálise na reforma psiquiátrica brasileira. Revista Latinoamericana de Psicopatologia Fundamental, 15(3), 524-539. https://doi.org/10.1590/S141547142012000300006

Goffman, E. (2008). Manicômios, Prisões e Conventos. Perspectiva.

Goidanich, M. (2001). Saúde mental na rede pública: possibilidade de inserção psicanalítica? Psicologia: Ciência e Profissão, 21(4), 26-33. https://doi.org/10.1590/ S1414-98932001000400004

Guerra, A. M. C. (2010). A psicose. Zahar.

Guerra, A. M. C., \& Generoso, C. M. (2009). Inserção social e habitação: modos dos portadores de transtornos mentais habitarem a vida na perspectiva psicanalítica. Revista Latinoamericana de Psicopatología Fundamental, 12(4), 714-730. https:// doi.org/10.1590/S1415-47142009000400007

Guerra, A. M. C., \& Vieira e Souza, P. (2006). Reforma psiquiátrica e psicanálise: diálogos possíveis no campo da inserção social. Psicología para América Latina, (5). http://pepsic.bvsalud.org/scielo.php?script=sci_arttext\&pid=S1870$350 \times 2006000100007$

Actualidades en Psicología, 35(130), 2021, 19-34 
Junior, B, P. M., \& Besset, V. L. (2012). Psicanálise e saúde mental: contextualizando o atendimento às demandas. Psicologia USP, 23(3), 523-538. https://doi.org/10.1590/ S0103-65642012000300006

Lacan, J. (2009). O seminário, livro 3: as psicoses. Jorge Zahar Editor. (Original publicado em 1981).

Laurent, E. (1999). O analista cidadão. Curinga Psicanálise e saúde mental, 1(13), 07-13. https://ebp.org.br/mg/wp-content/uploads/2020/06/Curinga-edicao_13.pdf

Lei 8080. Dispõe sobre as condições para a promoção, proteção e recuperação da saúde, a organização e o funcionamento dos serviços correspondentes e dá outras providências. Diário oficial da união (1990). http://www.planalto.gov.br/ ccivil_03/leis/l8080.html

Lobosque, A. M. (2003). Clínica em movimento: por uma sociedade sem manicômios. Garamond.

Lüchmann, L. H. H., \& Rodrigues, J. (2007). O movimento antimanicomial no Brasil. Ciência \& Saúde Coletiva, 12(2), 399-407. https://doi.org/10.1590/S1413-81232007000200016

Mendes, K. D. S., Silveira, R. C. de C. P., \& Galvão, C. M. (2008). Revisão integrativa: método de pesquisa para a incorporação de evidências na saúde e na enfermagem. Texto \& Contexto - Enfermagem, 17(4), 758-764. https://doi.org/10.1590/S010407072008000400018

Ministério da Saúde (2013). Saúde Mental. Cadernos de Atenção Básica. http://bvsms. saude.gov.br/bvs/publicacoes/cadernos_atencao_basica_34_saude_mental.pdf

Monteiro, C. P., \& de Queiroz, E. F. (2006). A clínica psicanalítica das psicoses em instituições de saúde mental. Psicologia Clínica, 18(1), 109-121. https://doi.org/10.1590/\$010356652006000100009

Monteiro, C. P., Linhares, H. de A., Barreto, E. K. M., \& Nascimento, Z. A. (2016). Soluções psicóticas e intervenções analíticas. ECOS-Estudos Contemporâneos da Subjetividade, 6(2), 188-196.

Muñoz, N. M. (2010). Do amor à amizade na psicose: contribuições da psicanálise ao campo da saúde mental. Revista Latinoamericana de Psicopatologia Fundamental, 13(1), 87-101. https://doi.org/10.1590/S1415-47142010000100006

Oliveira, H. M. D., \& Neves, T. I. (2012). O fenômeno e a estrutura: do diagnóstico desorientado ao diagnóstico orientado pela psicanálise. Cadernos de psicanálise, 34(26), 125-143. http://pepsic.bvsalud.org/pdf/cadpsi/v34n26/a09.pdf

Palombini, A. de L., \& Rocha, L. P. (2017). A clínica do Acompanhamento Terapêutico como pesquisa psicanalítica: uma escrita compartilhada entre vários. Ágora: Estudos em Teoria Psicanalítica, 20(3), 732-742. https://doi.org/10.1590/1809-44142017003012

Pena, B. F. (2017). A construção do caso em saúde mental como meio de sustentar o discurso do analista na instituição. Estudos de Psicanálise, (47), 135-140. http://pepsic.bvsalud. org/scielo.php?script=sci_arttext\&pid=S0100-34372017000100011\&lng=pt\&tlng=pt.

Perón, P. R., \& Dunker, C. (2002). Usos e sentidos da cura na psicanálise de Freud. Percurso Revista de Psicanálise, 15(28), 83-90.

Quadros, R. B., Martins, K. P. H., \& Soares, A. K. S. (2018). Psicanálise e saúde mental: um estudo sobre o estado da arte. Revista Subjetividades, 18(1), 119-131. https://doi. org/10.5020/23590777.rs.v18i1.6289 
Quinet, A. (2006). Teoria e clínica da psicose. Forense Universitária.

Quintanilha, B. C., Belotti, M., Tristão, K. G., \& Avellar, L. Z. (2017). A produção do cuidado em um centro de atenção psicossocial infanto juvenil. Mental, 11(20), 261-278.http://pepsic.bvsalud.org/scielo.php?script=sci_arttext\&pid=S167944272017000100014\&lng=pt\&tIng=pt

Rabêlo, F. C., Dias, R. R., Carvalho, G. de O., \& Martins, K. P. H. (2018). Esquizofrenia, clínica e saúde mental na psicologia sócio-histórica e na psicanálise. Psicologia Clínica, 30(2), 229-247. http://dx.doi.org/10.33208/PC1980-5438v0030n02A02

Ribeiro, A. M. (2005). O lugar do psicanalista em uma clínica das psicoses: algumas reflexões. Psychê, 9(16), 165-182. http://pepsic.bvsalud.org/scielo.php?script=sci_ arttext\&pid $=$ S1415-11382005000200011\&lng $=$ pt\&tlng =pt

Rinaldi, D. L. (2006). Entre o sujeito e o cidadão: psicanálise ou psicoterapia no campo da saúde mental? Em S. Alberti., \& A. C. Figueiredo (Orgs.), Psicanálise e saúde mental: uma aposta (pp. 141-148). Companhia de Freud.

Rinaldi, D. L. (2015). Micropolítica do desejo: a clínica do sujeito na instituição de saúde mental. Ciência \& Saúde Coletiva, 20(2), 315-323. https://doi.org/10.1590/141381232015202.17332013

Rinaldi, D. L., \& Bursztyn, D. C. (2008). O desafio da clínica na atenção psicossocial. Arquivos Brasileiros de Psicologia, 60(2), 32-39.

Rotelli, F. (1990). A instituição inventada. Em F. Rotelli., O. Leonardis., M. Diana., \& C. Risio. Desinstitucionalização (pp.89-99). Hucitec.

Santos, C. M. da C., Pimenta, C. A. de M., \& Nobre, M. R. C. (2007). The PICO strategy for the research question construction and evidence search. Revista latino-americana de enfermagem, 15(3), 508-511. https://doi.org/10.1590/S0104-11692007000300023

Stevens, A. (2007). Instituição: prática do ato. Em J.A. Miller., \& J. Miller. Pertinências da psicanálise aplicada (pp. 90-99). Forense Universitária.

Tenório, F. (2001). A psicanálise e a clínica da reforma psiquiátrica. Rios Ambiciosos.

Tenório, F., Costa-Moura, F., \& Lo Bianco, A. C. (2017). Tradição clínica da psiquiatria, psicanálise e práticas atuais em saúde mental. Psicologia USP, 28(2), 206-213. https://doi.org/10.1590/0103-656420150125

Thomas, J., \& Harden, A. (2008). Methods for the thematic synthesis of qualitative research in systematic reviews. BMC medical research methodology, 8(45). https://doi. org/10.1186/1471-2288-8-45

Travaglia, A. A. da S. (2014). Psicanálise e saúde mental, uma visão crítica sobre psicopatologia contemporânea e a questão dos diagnósticos. Psicologia Revista, 23(1), 31-49. https://revistas.pucsp.br/index.php/psicorevista/article/viewFile/20213/15042

Urra Medina, E., \& Barría Pailaquilén, R. M. (2010). Systematic Review and its Relationship with Evidence-Based Practice in Health. Revista Latino-Americana de Enfermagem, 18(4), 824-831. https://doi.org/10.1590/S0104-11692010000400023

Vieira, P. P. (2015). Reflexões sobre a história da loucura de Michel Foucault. Revista Aulas, 7(3). https://www.ifch.unicamp.br/ojs/index.php/aulas/article/view/1934 
Viganò, C. (2010). Avaliação e evidência clínica na saúde mental. Revista Latinoamericana de Psicopatologia Fundamental, 13(3), 469-481. https://doi.org/10.1590/S141547142010000300007

Vilhena, J., \& Rosa, C. M. (2011). A clínica psicanalítica nos espaços abertos do CAPS. Arquivos Brasileiros de Psicologia, 63(3), 130-147. http://pepsic.bvsalud.org/scielo. php? script=sci_arttext \&pid=S1809-52672011000400011\&lng=pt\&tlng=pt

World Health Organization (2014, March 30). Mental health: strengthening our response. https://www.who.int/en/news-room/fact-sheets/detail/mental-healthstrengthening-our-response 